\title{
Políticas públicas e linguagem: o papel das definições oficiais para a construção das capacidades estatais
}

\author{
Bruno Moretti \\ Doutor em Sociologia (Universidade de Brasília) \\ Professor visitante da Universidade de Brasília \\ Brasília,Brasil \\ bmoretti1@gmail.com
}

Elton Bernardo Bandeira de Melo

Doutorando na Universidade de Brasília

Analista de Planejamento e Orçamento do Ministério do Planejamento

Brasília, Brasil

eltonbandeira@gmail.com

Resumo

O objetivo deste trabalho, de natureza teórica e metodológica, é demonstrar que a abordagem das capacidades estatais deve apreender o campo burocrático também em sua dimensão simbólica. Considera-se que os atos de Estado, segundo a teoria de Pierre Bourdieu, constroem princípios de visão e divisão universalmente reconhecidos, produzindo efeitos sobre a realidade social. Será mostrado que os agentes estatais concentram poder simbólico pelo qual elaboram a linguagem da ordem pública e produzem proposições universais que definem, em interação com outros agentes, um espaço de possíveis para as políticas públicas, com instrumentos que só existem baseados num corpo de definições reconhecidas do interesse comum. Conclui-se que as capacidades estatais dependem da distribuição de poderes entre os agentes para criar definições legítimas, articulando séries de representações sociais e instrumentos de ação socialmente autorizados como práticas públicas.

Palavras-chave: capacidades estatais, poder simbólico, Pierre Bourdieu, representações sociais, políticas públicas.

\section{Introdução}

Qualquer indivíduo interage com o Estado diariamente. E não apenas quando está diante do agente público 
como algo físico, como quando se comporta bem em frente ao policial ou frequenta a universidade pública.Ao falar a língua oficial, respeitar as regras de trânsito ou tratar como doutor o indivíduo cuja identidade social é lastreada no diploma, o indivíduo não está diante de um "Estado tangível", mas se submete a categorias de percepção que considera tão naturais que sequer pensa como elas poderiam ser diferentes.

Essas categorias existem como uma espécie de consenso social a que cada um adere espontaneamente. $\mathrm{O}$ que há de comum a elas é que só são legítimas por serem homologadas socialmente na medida em que estão fundamentadas no pressuposto não problematizado da autoridade pública. O Estado existe não apenas como objetividade, mas também como uma espécie de ficção repleta de efeitos de realidade, um tipo de estrutura que existe porque tendemos a acreditar espontaneamente nela.

O Estado está do lado daquilo que entendemos como público, em oposição ao interesse particular. Nesse sentido, ele define a si próprio como a esfera de realização do interesse geral. Mas como e quem define o que é este domínio relativamente autônomo do público? Por que a língua oficial não é um dialeto? Por que alguém é classificado como irregular se não está em conformidade com os regulamentos burocráticos?

O campo estatal é um princípio de construção das identidades sociais ao estabelecer as categorias oficiais (regular x irregular, diplomado x não-diplomado, entre outros). É preciso problematizar as definições oficiais que estruturam a prática social: que agentes estão habilitados a dar definições oficiais? Quais os efeitos dessas definições sobre as políticas públicas? Como se distribuem as vantagens e ônus das definições autorizadas?

$\mathrm{O}$ artigo lida com essas questões. O que está subjacente a elas e será aqui desenvolvido é a tese de que não se pode compreender o Estado sem colocar em suspenso a naturalização das categorias de pensamento que ele institui como realidade. É possível entender os atos de Estado como a construção de princípios legítimos de classificação social, superando-se a definição que o Estado aplica a si mesmo, segundo a qual ele é uma realidade neutra e passiva, veículo de realização do interesse coletivo.

Espera-se mostrar que os instrumentos de ação pública só existem caso se possa crer e reconhecer que atendem ao interesse coletivo. Não há como pensar em um espaço de intervenções públicas (isto é, em políticas públicas, voltadas a resolver problemas classificados como coletivos) sem implícita ou explicitamente acreditarmos, mesmo diante de conflitos entre pontos de vista, em um domínio público, isto é, sem nos habituarmos a definições que instituem uma fronteira entre o público e o privado, delegando ao primeiro a gestão do que é apreendido como universal, nos limites de um território.

Aborda-se o tema da construção de um domínio público como condição para a existência de políticas públicas. Por seu turno, um domínio público só se efetiva se há agentes estatais que concentram o recurso da palavra oficial, entendida como aquela que institui algo publicamente, funda princípios legítimos de divisão social ao estabelecer classificações oficiais, opondo-se às perspectivas tomadas como particulares. Procura-se mostrar que as definições autorizadas como equivalentes de uma moral pública são constitutivas das possibilidades de ação estatal. 
A próxima seção aborda a discussão sobre as capacidades estatais, passando-se à tese de que as políticas públicas são também constituídas de palavras e linguagens. Posteriormente, são exploradas as contribuições de Pierre Bourdieu a uma sociologia do Estado cujo ponto central é a relação entre a ação estatal e a distribuição dos recursos entre agentes que competem pelo poder de criar e falar em nome do interesse público. Essa relação será explorada em maiores detalhes nas notas conclusivas, em que se argumentará que as capacidades estatais não podem ser pensadas sem referência a uma ordem simbólica.

\section{A abordagem das capacidades estatais}

A abordagem das capacidades estatais tem o mérito de recolocar o Estado como objeto de análise em matéria de políticas públicas. Autores ligados a diferentes correntes lidam com o Estado como se suas instituições simplesmente expressassem as forças políticas e os significados hegemônicos no espaço público. Nesse contexto, o Estado seria lido como resultante dos condicionamentos políticos, ideológicos e culturais da sociedade, sem se questionar sobre os recursos concentrados no âmbito estatal, em razão dos quais ele seria capaz de produzir efeitos para além das demandas de grupos específicos. Vale ilustrar a posição com passagem de Habermas (1995), para quem o poder do diálogo funda as condições para a ação administrativa do Estado.

A geração informal da opinião desemboca em decisões eleitorais institucionalizadas e em decisões legislativas por meio das quais o poder gerado comunicativamente se transforma em poder passível de ser empregado em termos administrativos [...] a força da integração social que tem a solidariedade social [...] deve poder desenvolver-se com base em amplamente diversificados espaços públicos autônomos e em procedimentos de formação democrática da opinião e da vontade políticas, institucionalizadas em termos de Estado de Direito; e, com base no meio do Direito, deve ser capaz de afirmar-se também contra os outros dois poderes - o dinheiro e o poder administrativo (Habermas, 1995, p.48).

Sob essa chave, o tema dos recursos concentrados na esfera estatal para responder a demandas sociais seria, no limite, irrelevante. O Estado constituiria um epifenômeno de variáveis externas a ele. Skocpol (1985), referindo-se aos estudos sobre o Estado nas décadas de 1950 e 1960 nos Estados Unidos, afirma que as pesquisas eram geralmente realizadas em termos de inputs ou outputs da ação estatal, mas nunca em relação ao governo em si mesmo. Em caminho distinto, o debate em torno das capacidades estatais procura tematizar o Estado em sua relativa autonomia, não sendo apreendido como reflexo dos interesses de grupos sociais (Skocpol, 1985).

Nessa perspectiva, não se nega a capacidade de influência política sobre a atividade estatal, mas ela não é reduzida a uma consequência das forças que determinariam seus contornos. Há toda uma variedade de posições dentro da agenda das capacidades estatais (Cingolani, 2013), mas importa frisar as perspectivas que não pensam o Estado como ator 
que centraliza as decisões e a execução de políticas compatíveis com seus objetivos, mas como instituições cuja força reside na capacidade de induzir arranjos para implementação de políticas públicas ${ }^{1}$. Tais arranjos são definidos como regras que criam as configurações dentro das quais uma política ocorre em meio à interação dos agentes.

As dimensões dos arranjos não se limitam às competências da burocracia, incluindo as de ordem política e relacional. Reconhece-se que o Poder Executivo está imerso em relações com três sistemas: o representativo, o participativo e o controle institucional (Pires; Gomide, 2016). As capacidades estatais não se circunscrevem aos temas tradicionais, como a existência de recursos humanos e orçamentários para a execução de políticas, mas também envolvem legitimidade, capacidade de mobilização e geração de consensos.

As capacidades estatais passam a ser examinadas em duas dimensões: técnico-administrativa, na qual se examina a competência das burocracias e os recursos necessários à execução de ações de governo; politico-relacional, que remete à inclusão dos atores nas políticas públicas, gerando consensos e coalizões (Pires; Gomide, 2016,).

A abordagem das capacidades estatais constitui grande salto explicativo em relação, por exemplo, às posições gerencialistas. Nos termos de Bresser-Pereira (1999), a assim chamada reforma gerencial no Brasil disseminou na alta administração pública conceitos como gerenciamento, desempenho e gestão, salientando a competência dos burocratas na definição de objetivos e na avaliação de seu alcance. Não é difícil observar que a ênfase reside no controle de métodos por parte da burocracia, que introduziria, como uma espécie de missão civilizatória, uma cultura de resultados nas estruturas de um Estado configurado por relações burocráticas e patrimoniais.

A distinção entre atividades de implementação e formulação é ilustrativa da concepção da reforma. As primeiras não precisariam ser executadas por estruturas estatais, devendo ficar sob a responsabilidade de atores dotados de maior eficiência. Com isso, o núcleo estratégico ficaria livre das tarefas executivas, podendo se dedicar à formulação e à avaliação de políticas.

Livre das atividades executivas, o núcleo estratégico estará em melhores condições para se dedicar a suas atividades gerenciais, que envolvem a formulação e a avaliação de políticas públicas e o acompanhamento ou controle das instituições descentralizadas sob sua supervisão (Bresser-Pereira, 2009, p. 328).

A passagem expressa a visão dos burocratas de núcleo estratégico como segmento que deve estar "livre" da atividade executiva, de modo que possa se entregar à formulação, à avaliação e ao controle. Mas é na execução que os modelos planejados e regras formais ganham realidade, convertem-se em prática e se encontram com a complexidade do "mundo real", irredutível aos modelos e às regras burocráticas, sendo atravessado por uma variedade de perspectivas, interesses e recursos dispersos.

A reforma foi pensada como um conjunto de mudanças necessárias para que o Estado pudesse se reestruturar e produzir resultados aos cidadãos. A capacidade da bu-

1 Aqui será utilizado como referência texto de Pires e Gomide (2016). 
rocracia de nível estratégico nas tarefas de formulação e avaliação era elemento central para modernizar a estrutura estatal. Um dos pressupostos a guiar os gerencialistas é que a execução, desde que entregue a atores privados ou a organizações mais flexíveis, não seria algo problemático. Ela é apreendida como consequência dos processos de formulação realizados por atores estratégicos capacitados para a tarefa.

O pressuposto da abordagem é que as políticas públicas atingem seus resultados se há capacidade gerencial e de formulação por parte de burocratas. Como eles estão "livres" das atividades de execução, os saberes relevantes não são os práticos, relacionados aos instrumentos e convenções que configuram o espaço de escolhas em uma política, mas os métodos gerais, que habilitariam os reformadores a aplicar às políticas uma linguagem gerencial, procurando thes atribuir racionalidade.

O que as abordagens gerencialistas deixam de fora é que as políticas públicas não se resumem a decisões ótimas baseadas em análises "racionais". Há um estoque de formas e procedimentos reconhecidos como linguagem própria a cada área e que constitui uma espécie de socialização àqueles que nela atuam. É sobre este estoque que incide qualquer método que procure "racionalizar" uma política pública, de modo que as inovações são efeitos de interações que incidem sobre a linguagem que organiza a política.

$\mathrm{O}$ estoque de formas sociais reconhecidas em cada área permite o consenso ou o dissenso regulado. Elas funcionam como um conjunto de representações sociais, ancoragens que dão nome às coisas e as classificam (Moscovici, 2003). As representações criam as condições para a interação na medida em que os agentes compartilham conceitos que fundam maneiras de apreender os espaços em que atuam. No entanto, tais representações não eliminam as tensões no interior de cada campo.

O conflito em torno das definições que estruturam as políticas públicas não é um elemento estranho a elas, mas uma propriedade imanente a ambientes complexos. A variedade de atores, interesses e perspectivas demanda mecanismos pelos quais alguma coordenação possa se estabelecer entre eles, buscando-se obter maior probabilidade de que uma cadeia de posições resulte em processamento de demandas por políticas públicas.

A noção de arranjo de implementação serve como base de questionamento da ênfase exclusiva na autonomia e profissionalização da burocracia para a produção de capacidades estatais. Às capacidades técnicas (não só voltadas à formulação e ao gerenciamento), os arranjos procurarão associar as maneiras como atores se combinam e cooperam (mesmo em circunstâncias de conflitos), acrescendo capacidade (pensada, inclusive, como legitimidade) às políticas públicas.

Diante do reconhecimento de que políticas públicas demandam legitimidade, é preciso abordá-las em sua dimensão linguística, abrindo-se à compreensão de como as possibilidades estatais se relacionam com as definições autorizadas. Nesse ponto, convém passar à próxima seção, que faz uma síntese do que se convencionou chamar "virada argumentativa". A ideia é que as políticas não são estruturadas por meio de uma racionalidade instrumental que define os meios mais eficientes para o alcance de objetivos. As políticas públicas têm natureza argumentativa e, ainda quando se valem de métodos que 
postulam caráter científico para apreender fenômenos, devem ser analisadas em termos da linguagem que empregam para construir visões.

A discussão sobre a "virada argumentativa" servirá de mote à ideia central deste artigo. Sua proposta é mostrar que soluções para problemas públicos se articulam às definições legitimadas em cada campo de política pública, que autorizam determinadas perspectivas e hierarquizam atores na medida em que eles se encontram mais ou menos próximos das definições consagradas.

A discussão sobre as capacidades estatais se desloca para a análise empírica em cada campo de política pública, buscando apreendê-lo como espaço de competição para impor representações que constroem as possibilidades da ação estatal. Sob essa chave, as políticas públicas são examinadas em seu espaço de possíveis, produto da luta pela imposição de definições legítimas, autorizando um conjunto de perspectivas, que se articulam ao interesse público.

\section{III - A virada argumentativa em políticas públicas}

A disciplina de políticas públicas nasceu sob influência do racionalismo. Lasswell (1951) tem importância central neste processo, pois procura estabelecer métodos científicos voltados ao estudo empírico das questões de governo ${ }^{2}$. O desenvolvimento da análise de políticas levou ao reforço da dimensão técnica, restringindo aspectos de outra ordem, sendo a disciplina usualmente representada pela ideia de um conhecimento empírico voltado a compreender como governos agem ou devem agir.

Diante desse enquadramento, cristaliza-se a imagem do analista de políticas públicas como especialista dotado de conhecimento técnico e neutro, apoiando instrumentalmente a decisão em conhecimento de leis causais, como se estivesse fora do jogo de interesses e visões de mundo. Ainda, segundo a abordagem em discussão, as políticas públicas são focadas na escolha do decisor, pressupondo uma implementação como mera execução do modelo teórico. Questões como a complexidade dos arranjos necessários à indução das agências implementadoras, a existência de conflito entre atores e a legitimação das decisões não são colocados em destaque. A política pública resulta da decisão baseada em conhecimento racional acerca da solução ótima para problemas governamentais.

Diversos autores mencionam uma guinada argumentativa na análise de políticas (Capella, 2015). Nesse contexto, salienta-se o caráter linguístico e a imbricação entre fatos e valores. Uma vez que eles não são plenamente separáveis, os resultados de modelos teóricos não apreendem leis causais objetivas, antes ratificando hipóteses de que parte o analista. No lugar da racionalidade instrumental, ganham ênfase aspectos como a argumentação sobre as escolhas, padrões de interação entre agentes e o papel do discurso na análise de políticas (Haajer; Laws, 2006).

2 Lasswell afirma que "o conhecimento dos processos decisórios implica estudos sistemáticos sobre como políticas são feitas e colocadas em prática” (Lasswell, 1971, p. 1). O autor postula ainda que o critério empírico envolve a distinção entre ciência e não-ciência. 
No âmbito da virada argumentativa, cabe destacar a obra de Majone (2005). O autor tem o mérito de assinalar a natureza discursiva das políticas públicas, chamando atenção para o fato de que as decisões não se esgotam nas análises instrumentais que apontam soluções ótimas, antes envolvendo argumentação, convencimento e produção de evidências. As políticas públicas são feitas também de palavras, devendo o analista ser alguém habilitado à persuasão, e não um tecnocrata que exaure seus saberes em métodos instrumentais.

Majone critica duas visões extremas. De um lado, nega a política pública como técnica fundada no ideal positivista da verificação empírica. De outro, descarta a validade da abordagem de políticas públicas como resultado dos grupos de interesse. Entre os extremos, propõe uma visão centrada na capacidade de construir evidências (definidas como seleção de informações voltada à argumentação), de modo a legitimar escolhas e persuadir o público.

O autor caminha em direção a uma espécie de horizonte habermasiano, aplicado às políticas públicas. A ênfase no caráter linguístico da análise reverte numa visão positiva do papel que a defesa de argumentos e a persuasão têm nas escolhas de políticas públicas em sociedades democráticas, levando a um processo contínuo de aprendizagem (Majone, 2005). A razão comunicativa funda consensos, entendimentos baseados no diálogo público, que têm o potencial de modificar opiniões e percepções.

A perspectiva deixa entrever uma visão edificante do diálogo na esfera pública, produzindo consensos fundados numa racionalidade comunicativa. Contudo, ela só se exerce na medida em que suspende formas de coerção e dominação que distribuem desigualmente a capacidade de falar.

No processo da política, há algo mais do que decisões; há também atividades de argumentação explicativa (empírica) e justificatória (valorativa) para oferecer ao público cidadão as razões pelas quais um governo decidiu fazer uma coisa e não outra [...] as decisões coletivas, ao menos nas democracias, requerem explicação, argumentação, difusão entre o público e, além de convincentes, ter capacidade de responder a seus opositores, vencer o ceticismo e despertar o consenso entre os cidadãos (AguilarVillanueva, 2005, p. 24-25).

Para se examinar como os problemas se tornam públicos, é preciso entender como são legitimadas as perspectivas. Em outros termos, faz-se necessário reconstruir as formas pelas quais as narrativas oficiais constituem sentidos, estabelecendo os princípios legítimos de visão e divisão do mundo social (Bourdieu, 2014).

O próprio Majone assinala que os modelos tradicionais de escolha racional supõem um sujeito que busca a otimização com base nas regras dadas. No entanto, os agentes sociais também competem pelas regras do jogo, tomando-as como objeto de sua ação nas arenas de política. O autor ilustra o argumento com a Lei de Seguridade e Higiene Ocupacional dos EUA (Occupational Safety and Health Act of $1970^{3}$ ), mostrando como a discussão no Parlamento norte-americano se concentrou em questões sobre quem e pls/oshaweb/owadisp.show_document?p_table=OSHACT\&p_id=2743>.Acesso em: 10 jan.. 2017. 
como deve ser aplicada a norma, além dos critérios que informariam a prática regulatória. Tais definições estruturam o espaço de possibilidades da política e redefinem poderes, na medida em que configuram um campo de escolhas.

Importa destacar que redefinições das questões públicas não são neutras, não apenas porque autorizam novas visões que informam práticas estatais, mas também porque redistribuem institucionalmente o poder de aplicação de soluções e utilização dos instrumentos que incidem sobre os problemas. As representações e imagens que sustentam uma política pública não podem ser encaradas apenas como restrições, na medida em que os atores não competem somente em torno de interesses materiais, mas também em razão das definições que dão forma oficial a uma política.

Não se deve conceber as políticas públicas apenas como espaços estruturados cujas definições legítimas constrangem as escolhas dos agentes. As próprias definições institucionalizadas são alvo do jogo político-institucional, podendo os agentes investir em sua mudança e dilatar o espaço de possíveis em direção a segmentos ou a soluções excluídas das representações oficiais. Nessa hipótese, as próprias capacidades estatais sofreriam alterações, rearticulando-se os arranjos institucionais, regidos por novas definições.

Os valores não importam em políticas públicas apenas como objetos que sustentam coalizões (Weible; Sabatier, 2007) ou comunidades epistêmicas (Haas, 1992). Eles devem ser apreendidos como prática discursiva, como processo ativo de construção de sentidos pelos agentes. Por essa razão, é necessário entender como eles interagem, atribuindo sentidos às questões das políticas públicas (Zittoun, 2014), de modo que possam associar problemas (desordem social) a causas e propostas a consequências (reordenamento possível), concatenando-os por meio de operações discursivas em meio a um jogo de linguagem que é simultaneamente um jogo de luta pela apropriação de recursos (Zittoun, 2016).

$\mathrm{Na}$ sequência, serão incorporadas ao debate as contribuições de Pierre Bourdieu a uma sociologia do Estado. Será abordado o conceito de campo burocrático, com a finalidade de mostrar seu potencial para apoiar a pesquisa sobre as capacidades estatais. Essas capacidades, vale frisar, pensadas especificamente em termos das definições que organizam o campo de cada política pública, autorizando práticas e instrumentos como soluções frente a problemas públicos, eles próprios, passíveis de ressignificação.

\section{O campo burocrático e suas propriedades}

Bourdieu (2014) abordou de forma sistemática o Estado, principalmente, numa série de cursos proferidos no Collège De France, reunidos em Sobre o Estado. Do ponto de vista histórico, o projeto de Bourdieu é explicar a transição do poder dinástico ao poder estatal, apreendido como espaço relativamente autônomo que se transforma em uma rede impessoal de caráter público.

A esfera estatal será produzida pelos agentes especializados em criar teorias daquilo que é representado como interesse geral. Os agentes que disputam este campo da gestão 
do universal criam o Estado como ficção jurídica, na medida em que atribuem a ele a propriedade do desinteresse. Esta é a singularidade mais relevante do campo burocrático, que o torna esfera concentradora dos recursos da força física legítima e da tributação (Weber, 1982; Elias, 1993), mas principalmente do poder de falar em nome do interesse geral.

Bourdieu salientará o poder estruturante do campo estatal, especialmente como sistema simbólico que autoriza pontos de vista na medida em que os enuncia como oficiais. Por outro lado, sua teoria requer que se examinem os agentes especializados do Estado, isto é, aqueles que se posicionam como agentes do oficial, construindo e reproduzindo uma ordem burocrática na medida em que são investidos do poder de representação do interesse público.

Tais agentes concentram instrumentos e linguagens específicos, falando como se encarnassem a razão impessoal de Estado. As formas que o agente oficial produz e reproduz o habilitam a falar em nome do que é público, de modo que, ao consagrá-las, consagra a si próprio como detentor de uma autoridade particular. O que está em jogo na constituição do Estado como esfera relativamente autônoma é a construção de um tipo de racionalidade, uma "ficção bem fundamentada" (Bourdieu, 2014, p. 94) que nos faz crer e reconhecer em toda uma dramatização do interesse público, expressa em maneiras de agir baseadas em procedimentos, registros, atestes, entre outros. Sob tais condições, o agente oficial só pode se afirmar na medida em que seu interesse específico é apreendido como o interesse geral, que converte seu dizer em palavra oficial.

Se, por um lado, Bourdieu aborda os movimentos associados à passagem histórica ao Estado como monopólio público, por outro, indica que os estudos sociológicos sobre o Estado devem se concentrar nos "pequenos objetos", nos produtos burocráticos usualmente relegados pela análise científica. Porque é neles que se expressa a linguagem burocrática; é por meio deles que perspectivas específicas se convertem em representações do interesse geral, definindo aquilo que será integrado à paisagem institucional como expressão do interesse comum.

Essas formas sociais, experimentadas como razão impessoal, devem ser desnaturalizadas pela análise sociológica. Em outros termos, devem ser retiradas de sua aparente neutralidade e seu efeito de evidência para que possam iluminar as condições sob as quais os agentes convertem perspectivas arbitrárias em matéria universal, isto é, como acumulam um crédito social, na medida em que definem a si mesmos como gestores do interesse público, monopolizando o poder de falar em seu nome por meio da delegação institucional.

Gusfield (1967) afirma que a lei não deve ser tomada apenas de forma instrumental, mas também como um padrão de moralidade pública. O ponto é saber como ele é construído, e, uma vez ancorado em instituições, é integrado à percepção coletiva como produto "natural" do interesse universal. Quem são os agentes que concentram os instrumentos e linguagens pelos quais é gerido este monopólio do universal? A resposta à questão levantada requer a apreensão do espaço burocrático em sua complexidade, descartando a premissa do Estado como ente homogêneo. 
Deve-se pensar no Estado como uma esfera em que agentes lutam pela capacidade de impor práticas e discursos sobre o interesse coletivo, combinando-os de modo a fabricar um domínio público. É preciso se referir não ao Estado, mas a atos de Estado, entendendo como agentes oficiais concentram recursos de ordem distinta. Tais recursos podem estar legitimados em votos, no domínio de procedimentos e técnicas, no poder de atestar a conformidade às regras, em valores, entre outros.

É necessário entender como as diferentes frações estatais interagem, mas também como se dão as relações entre agentes estatais e não-estatais, mediadas pelos recursos que cada um detém. O ponto não é em que medida o Estado espelha adequadamente a soma de interesses privados, mas como os segmentos lutam para dominar os recursos estatais, procurando incidir sobre as formas oficiais de classificação que naturalizam no espaço público sentidos mais ou menos inclinados aos interesses de cada grupo.

Em síntese, agentes sociais (estatais ou não) interagem e lutam pelo poder de definir aquilo que, no campo burocrático, será representado como coerente com a razão impessoal. Os que detêm o reconhecimento de que atuam como especialistas das diferentes frações burocráticas dominam a linguagem dos instrumentos de Estado e estão habilitados a apontar as soluções técnicas definidas como adequadas ao tratamento dos problemas públicos, na medida em que são reconhecidas como desinteressadas, denegando seu caráter valorativo. $\mathrm{O}$ capital de palavras (de falar em nome do universal, do desparticularizado) é também um capital de soluções públicas, de apresentar as saídas para problemas coletivos (Bourdieu, 2014).

Os bens simbólicos também são escassos, de modo que não está aberta a qualquer agente a legitimidade para falar em nome do coletivo, apresentando as saídas para os problemas públicos, em especial em momentos de crise. A legitimidade não deriva de uma régua que mede a capacidade técnica de cada agente. Essas técnicas só existem em meio a definições autorizadas, que tem o poder de inscrever no espaço social esquemas de percepção e avaliação pelos quais se apreende o que é passível de ser feito em nome do público.

Bourdieu (2014) afirma que o Estado está do lado dos inventos organizacionais. O ofício, os autos, a comissão, entre outros, são instrumentos de construção de uma razão de Estado. Eles supõem sujeitos que concentrem o recurso peculiar que é a linguagem própria ao público, a palavra representada como desinteressada, sem a qual não se integra o jogo burocrático. Os atos de Estado são capazes de construir a realidade social, na medida em que o capital de palavras se liga ao poder de oferecer soluções legítimas, reunindo competências, aplicando regras e autorizando a transgredi-las.

No entanto, os "inventos burocráticos” também criam restrições à ação estatal, ao concentrarem poderes em agentes detentores de recursos que fecham o Estado em um espaço de possíveis que tende a ser naturalizado como único pensável. Abrir este espaço de possibilidades envolve articular soluções propostas a uma moralidade pública. Para tanto, há de se somar recursos determinados, que incidem sobre as representações cristalizadas em instituições pelas quais se define aquilo que é percebido como interesse universal.

A abordagem aqui exposta envolve mudar a própria concepção do que são e fazem atores centrais no Estado. Primeiro, o que eles não são, a despeito da maneira como po- 
dem se definir: não são elaboradores de programas, traçando metas que determinam os eventos; não são definidores do que cada implementador fará; não são avaliadores de suas decisões, corrigindo-as racionalmente na medida em que a prática (subproduto negativo do modelo) distorceu os rumos pensados.

Ainda que os agentes representem a si próprios nesses termos (como o núcleo estratégico de Bresser-Pereira), é preciso suspender a representação oficial do oficial. Aqui reside o papel da sociologia do Estado numa abordagem das capacidades estatais. É necessário vincular definições oficiais aos instrumentos de ação pública, compreendendo as ações estatais como práticas estruturadas pela concentração de recursos em ambientes complexos e marcados pela incerteza.

O ponto decisivo é a distribuição dos recursos materiais e simbólicos, esses últimos, definindo quem pode falar/fazer e o que pode ser dito/feito em nome da categoria do universal. Por outro lado, a estrutura não pode ser pensada a-historicamente, mas como resultado da luta entre os agentes, em especial, pelo poder de incidir sobre as representações oficiais e sobre as práticas que as materializam. A distribuição dos recursos no espaço social não é mera restrição ao agir, antes devendo ser apreendida como ferramenta que potencializa as interações, das quais emergem os sentidos apreensíveis pelos atos de Estado e, em última instância, as capacidades para o Estado processar demandas.

É preciso avaliar criticamente as teorias sobre capacidades estatais, uma vez que elas recaem numa espécie de fisicalismo, tendente a enfocar aspectos tangíveis do Estado. Os estudos, em geral, salientam diferentes tipos de capacidade, como a fiscal, a coercitiva e a administrativa. Esquecem-se, contudo, que todas essas capacidades só existem em meio ao poder do Estado em criar definições oficiais, submetendo os agentes a princípios legítimos de visão social.

Em geral, a capacidade estatal se refere a uma ou à combinação das seguintes dimensões do poder estatal: a) coercitiva/militar; b) fiscal; c) administrativa/ implementação; d) transformativa ou industrializante; e) relacional/cobertura territorial; f) legal; g) política (Cingolani, 2013, p. 27).

Não fosse a dimensão simbólica do Estado, o uso da força fisica seria a regra. O pressuposto irrealista de tal posição seria uma dominação direta, sem a mediação de uma ordem simbólica. O consentimento remete justamente àquilo que Bourdieu (2014) denomina poder simbólico, o poder estatal de dissipar no tecido social definições legítimas, representações sobre o que pode ser feito em nome do interesse público.

Para citar um importante autor no debate sobre as capacidades estatais, Evans (2011) elenca entre os pontos para a construção de um Estado desenvolvimentista no século XXI o poder de perseguir objetivos coletivos globais. O problema é que não há uma expressão natural do interesse comum, remetendo às indagações sobre quem e como se define o que são as questões coletivas, passíveis de atenção pública.

A habilidade do Estado em perseguir coerentemente objetivos coletivos, e não responder às demandas imediatas subjetivamente definidas dos membros 
individuais da elite, ou organizações particulares da elite, é ainda mais essencial do que o trabalho anterior sobre o Estado desenvolvimentista sugeriu (Evans, 2011, p. 10).

$\mathrm{Na}$ perspectiva aqui esboçada, capacidades estatais devem ser lidas como a acumulação de poderes materiais, simbólicos e organizacionais para autorizar socialmente a solução de problemas públicos e construir representações sobre a natureza dos problemas. Nenhum tipo de poder pode ser dissociado do capital simbólico, que é também um capital de soluções, um capital (assimetricamente distribuído) de confiança no poder de enunciar a saída da crise, o rumo do desenvolvimento e assim por diante.

Ele pode também ser apreendido como a capacidade de preencher e fixar os sentidos deslizantes do signo vazio (Deleuze, 2015) a que damos o nome de interesse coletivo. Em outros termos, as palavras oficiais, ao institucionalizarem princípios de visão e divisão social, classificam as coisas no mundo. Dizem, em particular, o que não é passível de ser aplicado como solução pública, o que é irregular e imprudente.

Nesses termos, a administração pública pode ser representada como uma série de princípios linguísticos que consagram uma visão sobre o que são o interesse universal e a razão imparcial. O Estado nos dota de um "isto é óbvio coletivo" (Bourdieu, 2014, p. 231), como se os princípios de classificação que ele cria fossem espontâneos, reflexos neutros de propriedades objetivamente existentes. No entanto, consagrar valores implica impor sentido ao mundo social, autorizar publicamente certas práticas em detrimento de outras. Envolve hierarquização de posições dos agentes sociais, mediante uma espécie de topografia com valor diferencial e status gerados pela maior ou menor proximidade das definições oficiais.

$\mathrm{O}$ agente oficial atua em meio a uma hierarquia valorativa radicada nas instituições ${ }^{4}$, que, a um só tempo, constitui o Estado como lugar do universal e o consagra na medida em que ele próprio encarna os princípios que lhe permitem falar em nome do público. A construção da imagem do interesse comum envolve a adesão tácita do agente oficial a uma série de pressupostos, que se manifestam a ele sob a forma de expectativas que deve preservar de modo a não produzir ruptura na definição da situação projetada em suas representações (Goffman, 2011).

Ao preservar tais expectativas, o agente mantém uma ordem, sob a forma de imagem que constrói de si como representante do universal, em meio a um ritual no qual se vale das linguagens, convenções e procedimentos reconhecidos como públicos. Assim produz juízos positivos a seu respeito e ratifica todo um sistema de valores (controle fiscal, prudência, economicidade e assim por diante).

A mudança no campo estatal só pode ser produzida se o agente a articula com valores consagrados, ainda que para lhes atribuir outros sentidos ou expandir seu alcance em direção a representações não autorizadas, legitimando-as na medida em que cria novas

4 Isto é, como um sistema de classificação, atribuindo maior ou menor crédito social aos agentes. Sua eficácia está associada à disseminação no espaço social sob a forma de regras e categorias de percepção. 
imagens e associações entre perspectivas, moralidade pública e interesse coletivo. A competição em torno do conteúdo de políticas públicas, por exemplo, é transfigurada para os sentidos apreensíveis na prática estatal. A luta dos grupos dominados (estatais ou não) deve se dar em torno da institucionalização de novos padrões institucionais, abrindo espaço a mudanças no campo burocrático e nos valores que ele torna oficiais (Fraser, 2001).

A depender dos resultados dessa competição, os atos de Estado podem implicar a ampliação do burocraticamente pensável, abrangendo linguagens até então interditadas. No limite, eles têm a capacidade de reconfigurar o poder simbólico dos grupos e constituir os canais para que eles se expressem como coletivo que dirige novas demandas ao Estado, renovando a hierarquia valorativa, num movimento com limite dado pelas condições de incidir sobre os sentidos inscritos na ordem oficial.

Nas notas conclusivas, serão exploradas as contribuições para uma análise das capacidades estatais da concepção teórica exposta, segundo a qual, estendendo o tradicional conceito weberiano, o Estado é a esfera detentora do monopólio simbólico da nomeação oficial.

\section{Notas conclusivas: capacidades estatais e a ordem simbólica}

É frequente pensar o campo das políticas públicas como construção de modelos que sustentam a decisão ótima em termos da melhor relação entre recursos e resultados pretendidos. Por outro lado, numa chave que a salienta a importância do diálogo com os atores, a melhor decisão será aquela que gera consenso e legitimidade.

No entanto, a decisão envolve a capacidade de reunir os poderes necessários a gerar efeitos, apreendidos como alargamento do espaço de possíveis. Não se trata apenas do melhor desenho em torno dos objetivos a atingir, do melhor modelo de causas e consequências e nem da interação com a sociedade civil mediante o diálogo. $\mathrm{O}$ ponto mais relevante na análise de políticas, partindo-se do referencial teórico apresentado, é a topografia social e a distribuição de recursos materiais e simbólicos que, somados, incidem sobre o espaço de possibilidades estabelecido.

O alargamento dos limites de um campo de políticas requer a alteração das representações sobre o que pode ser dito e feito em nome do interesse público. E tais representações não são ideias abstratas soltas no ar, mas estão ancoradas nos esquemas de percepção dos agentes e nas regras do jogo estabelecidas. Isto é, a ordem radica na coincidência entre a dimensão objetiva (burocracias, regras, procedimentos) e a subjetiva (formas de percepção pelas quais os agentes reconhecem os princípios de classificação que estruturam o espaço social), fundando uma espécie de conformismo lógico e moral que submete os agentes a um conjunto de definições (Durkheim, 1965).

$\mathrm{Na}$ análise de cada campo, é preciso recompor as categorias centrais que estruturam os sentidos ordinários, desvelando a maneira como elas se combinam, as relações internas entre os seus termos, as interdições e as possibilidades. Deve-se adotar um método relacional, pelo qual as ideias estão associadas (nunca de maneira mecânica) ao lugar ocupado 
por cada agente e o lugar só é devidamente compreendido na relação com as outras posições. As definições de cada campo, cristalizadas como regras, articulam-se a um conjunto de práticas reconhecidas como instrumentos de ação pública, distribuindo poderes àqueles que concentram os recursos para empregá-los e controlá-los.

É substantivo o peso do já dito e cristalizado sobre as capacidades estatais. Ele implica excluir alternativas, desclassificá-las ou torná-las invisíveis. De uma série de teóricos da implementação, críticos às teorias top-down ${ }^{5}$ (Berman, 1978; Majone; Wildavsky, 1984; Lindblom, 1959), traz-se a ideia de que políticas públicas não se resumem a modelos causais que desenham programas. $\mathrm{O}$ avanço é lento, sujeito à incerteza e à política. A lógica da ação estatal não é devidamente desvelada se penada apenas como modelo normativo, conforme a tradição top-down,em que checklists (Mazmanian; Sabatier, 1993) constituem o padrão em consonância com o alcance de objetivos.

Avaliar o grau em que arranjos de implementação atendem às prescrições do planejado é, no mínimo, limitado ${ }^{6}$. A análise das capacidades estatais não deve reverter em modelo normativo. $\mathrm{O}$ caráter relacional do espaço social não se confunde com modelos lógicos que prescrevem o que agentes devem fazer para atingir seus objetivos. A estrutura de um campo só existe enquanto razão prática dos agentes. Do contrário, a subjetividade (sob a forma de ideias e interesses) torna-se um resíduo do modelo, uma mancha nas previsões conceituais.

As teorias normativas demandam a construção de uma cadeia causal clara da elaboração à implementação, atribuindo aos conflitos e às ambiguidades o poder de determinar o fracasso no alcance de objetivos. No entanto, o conflito e a ambiguidade são constitutivos dos campos de política (Matland, 1995). A construção de mecanismos que induzam à cooperação não pressupõe a inexistência de conflitos, antes sendo uma resposta a eles (Cline, 2000).

Os conflitos são indissociáveis do poder dos agentes em controlar a linguagem e os procedimentos socialmente homologados em cada espaço social, autorizando-os a falar e a agir em nome do interesse comum. Gusfield (1984) afirma que analisar a lógica dos problemas públicos significa buscar a ordem na qual eles emergem na arena pública, havendo três aspectos fundamentais. O primeiro, a "propriedade" (Gusfield, 1984, p. 10),

5 “Teorias top-down partem da hipótese de que a implementação de política inicia como uma decisão tomada pelo governo central. Teóricos top-down essencialmente seguiram uma abordagem prescritiva que interpretou a política como input e a implementação como fator de output" (Pülzl; Treib, 2007, p. 90-91).

6 Para uma ilustração, ver Loureiro et al (2014), que procuram cotejar o Programa Minha Casa Minha Vida com as dimensões das capacidades estatais. Mais do que uma abordagem normativa que avalia em que medida programas atendem a dimensões das capacidades estatais, é preciso reconstruir os recursos que os agentes dispõem para incidir sobre a palavra oficial e como se dá concretamente a interação entre eles, mostrando como o programa absorve as posições heterogêneas de grupos e cria canais, sob a forma de linguagem oficial, para processar suas demandas em meio ao conflito de perspectivas.

7 A expressão original é “ownership", consistindo de uma metáfora pela qual Gusfield pretende examinar quem tem o poder de definir e descrever o problema. 
designando o poder diferencial de grupos definirem o que são os problemas públicos. Mas não bastar indagar quem são os titulares da nomeação do problema, devendo-se associá-la à capacidade de atribuir responsabilidades políticas (pela solução do problema) e causais (estabelecimento de relações de causalidade).

As definições que estruturam cada campo de ação coletiva não são um estágio preliminar das políticas públicas, pensadas como um ciclo de etapas segregadas. Antes constituem um espaço de possíveis em que representações e instrumentos de ação guardam relações de dependência recíproca, movimentando-se em decorrência das flutuações dos termos que os associam e geram as categorias legítimas que organizam um espaço heterogêneo, distribuindo os agentes em função dos sentidos apreensíveis pela prática estatal.

Mas os agentes não são pontos distribuídos num espaço objetificado, uma vez que sua posição os habilita a agir, a incidir sobre o Estado, visando a produzir sentidos, a criar uma ordem política por meio do encadeamento entre problemas e soluções (Zittoun, 2016). Se capacidades estatais podem ser pensadas em sua relação com resultados de políticas públicas (Pires; Gomide, 2016), quando tomada a dimensão simbólica, tal relação tem que ser analisada em termos da capacidade de cada arranjo dispor em conjunto, colocar em série definições e práticas, problemas e soluções, agentes e instrumentos. Portanto, não se trata de construir modelos ou apenas formular objetivos consistentes, tampouco de extinguir conflitos.

A questão reside na probabilidade de gerar efeitos ao combinar recursos ou propriedades dos agentes, ao articular séries heterogêneas, estabelecendo correlações a partir das categorias que definem cada campo e lhe atribuem sentidos. Esses não designam significados das coisas, mas são efeitos dos conjuntos elaborados e das formas variáveis que assume o signo vazio do interesse coletivo ${ }^{8}$, circulando entre as séries e pondo em relação o que se pode fazer e o que se pode falar no domínio público.

A dimensão político-relacional não necessariamente deve ser invocada à luz da produção de consensos. Por exemplo, novas práticas podem abrir um espaço de representações, combinando-se de forma inédita com diretrizes gerais, mesmo diante do conflito. Ainda que a questão não possa ser tratada em detalhes, é o caso do Programa Mais Médicos, que, integrando ensino-serviço sob nova perspectiva (articulando séries), reverteu uma curva de desaprovação (para a qual foi decisiva a oposição das associações médicas), diante da integração de milhares de médicos à atenção primária em locais onde havia falta desses profissionais (Campos; Pereira Júnior, 2016). O exemplo ilustra que novos instrumentos podem redefinir categorias que estruturam as práticas de cada setor, fazendo deslizar as relações entre teoria e prática. Ademais, expõe a fragilidade do raciocínio racionalizante que vai do geral ao específico para prescrever modelos de políticas públicas e impor requisitos às políticas, como a construção do consenso.

8 Sobre o pensamento por séries heterogêneas, que concatena elementos, define seu jogo de relações e cruzamentos, ao mesmo tempo em que os toma em sua diferença constitutiva, como sistemas de dispersão, ver Foucault (2016) e Deleuze (2015). 
Conclui-se que a interação não é um subproduto dos modelos conceituais. Os efeitos do Programa ocorrem em meio ao deslocamento das posições relativas dos agentes na medida em que se introduzem no espaço articulações entre enunciados e instrumentos de ação. $\mathrm{O}$ exemplo do Mais Médicos indica que, no lugar de aplicar uma teoria prescritiva às políticas públicas, deve-se entender como recursos e poderes se convertem em ação, reposicionando grupos e capacidades à luz dos novos sentidos.

Para uma análise de políticas capaz de explicar como se dão as interações entre os agentes, há de se suspender a presunção de equivalência entre teorias de formulação de programas e as condições para que eles existam no espaço social e gerem resultados (como se eles derivassem exclusivamente de um modelo causal correto). Em seu lugar, o analista deve identificar, diante do espaço estruturado do campo burocrático, os limites que a política "toca" e o peso das palavras que criam as representações oficiais em cada campo. A estabilidade de uma política requer definições cristalizadas ${ }^{9}$. De outro lado, só há novas soluções possíveis a problemas oficiais se elas se valem ou reconfiguram a linguagem que fabrica incessantemente, pela articulação de séries, a ideia de público, incidindo sobre visões naturalizadas.

Se tomado novamente o Sistema Único de Saúde, pode-se perceber a heterogeneidade entre os discursos sobre o público e instrumentos de ação, revelando que o ponto fundamental é o poder que têm os agentes para concatená-los. Por exemplo, toda a expectativa em termos de uma saúde pública de qualidade, com restrições que são tratadas usualmente sob a forma de falhas de gestão (por exemplo, para a disponibilização de medicamentos), não reverte espontaneamente em regras que predispõem à aquisição de insumos de forma mais eficiente. Um exame superficial da execução em saúde mostra que o risco de se obter uma licitação deserta pesa menos do que o de penalização dos agentes (em razão dos preços praticados, das modalidades de licitação escolhidas, entre outros).

Essa hierarquia de valor não é um produto consciente da escolha dos agentes, mas um modo de agir apreendido praticamente, sob a forma, inclusive, de sanções que criam uma gestão pública movida pelo medo, na qual não decidir é um modo de (não)ação mais seguro e isento de riscos, em relação à decisão de fazer algo. $\mathrm{O}$ exemplo, ainda que tratado sem detalhes, demonstra que a ideia espontânea de que um sistema de contratações deve atender ao interesse público não é trivial. As regras contratuais que estruturam as possibilidades da administração pública impõem ao campo estatal definições tácitas que hierarquizam valores, fazendo o interesse público encarnar em perspectivas específicas, como a austeridade e o controle.

No caso citado, os agentes que criam e consagram a hierarquia são, por exemplo, os que constroem o entendimento doutrinário, os que elaboram as regras do sistema de contratos e os agentes de controle com poderes para nomear como regular a execução

9 A ideia de que a permanência de uma política pública por longo período requer um consenso sobre valores é explorada por teorias como a do equilíbrio pontuado (Baumgartner; Jones; Mortensen, 2014) e de coalizões de defesa (Weible; Sabatier, 2007). No entanto, elas não investigam como os sentidos nascem da interação concreta entre agentes. 
contratual. Compreender o espaço de possíveis que daí resulta envolve entender os recursos que os agentes concentram, os instrumentos representados como consonantes ao interesse público (associado predominantemente ao controle) e as linguagens que autorizam a falar e a postular reconhecimento. Apenas indagando pelas propriedades dos agentes é que se pode recompor sua distribuição no espaço social e a concentração do crédito social para falar em nome do público, impondo soluções admissíveis.

O ponto não é se o consenso em torno da regra está coberto, como se fosse um item do checklist elaborado pelos especialistas em criação de programas. Pires e Gomide (2016) estudam casos específicos em que a interação com o sistema de controle repercutiu positivamente sobre os resultados, mas essa é uma questão a ser tratada no limite de cada política ${ }^{10}$. Em situações como as descritas anteriormente (regras contratuais $\mathrm{x}$ demandas de saúde), o peso da variável controle sobre as práticas é grande. A modificação deste quadro exige não necessariamente um consenso, mas canais para rearticular regras e discursos sobre o público.

Disso poderia resultar, por exemplo, o estímulo a contratos plurianuais para serviços continuados, menor ênfase em aspectos formais, prazo mais extenso de validade de atas de registro de preço e indução para adesão a atas entre entes federados como hipótese de dispensa de licitação. As mudanças poderiam implicar um conflito de representações, considerando-se os agentes mais inclinados à articulação do interesse público com o controle, materializada em procedimentos que impõem à execução uma série de obstáculos, posicionando-a com sinal contrário em relação ao interesse coletivo.

Para tanto, o decisivo é criar as possibilidades para se constituir novas séries de relações entre os termos que organizam uma área (contratos-desburocratização-demandas de saúde, por exemplo). Refazer a relação entre os termos é condição para a fixação de novas definições, envolvendo práticas e soluções. As palavras podem constituir a realidade ao falar dela. As redefinições são cruciais na medida em que alargam o espaço de possíveis, mas só são eficazes se acompanhadas do poder de quem as enuncia de fazer crer e reconhecer que fala em nome do interesse coletivo (Bourdieu, 2006). O grupo (em nome do qual nasce uma política pública) também se constitui sob a forma de delegação (geralmente, inconsciente) àquele que fala em seu nome e, ao fazê-lo, cria (ou incide sobre) representações (Bourdieu, 1990).

Alterar uma regra envolve conhecê-la por dentro; supõe, portanto, apropriar o capital de palavras, saber transgredir a regra falando em seus termos (Bourdieu, 2014), configurando um poder simbólico que é também um poder de oferecer soluções, empregar técnicas homologadas, articuladas às representações do interesse universal. As práticas públicas envolvem a construção do instrumento adequado (o protocolo, a regra, o cadastro), mas esse só se coloca como prática oficial se integra o discurso que representa o público, a teoria que não só descreve como cria a ideia do que é o público. O recurso citado é o capital cultural sob a forma de capital burocrático.

10 Os autores salientam que os resultados de sua investigação não são generalizáveis, circunscrevendose aos casos examinados (Pires; Gomide, 2016). 
[...] Há uma espécie de vaivém permanente entre as inovações práticas em matéria de protocolos, nas relações entre o rei e o Parlamento - e as inovações teóricas destinadas a legitimar essas pequenas conquistas práticas: almofada vermelha e toga vermelha etc. Há, portanto, um imenso trabalho de construção de práticas públicas, inseparável de um trabalho de construção de um discurso de serviço público, de um discurso destinado tanto a descrever como a construir [...] essa realidade sem precedente [...] que é o público (Bourdieu, 2014, p. 440).

O Estado não é só estrutura. É também um espaço no qual os agentes têm como alvo a construção performática dessa realidade que é o público. Por outro lado, os agentes não fazem o que querem a qualquer tempo. Criam, mas são produto das formas consagradas, que inscrevem no interior de cada espaço as maneiras naturalizadas de se representar o que é o universal, em oposição ao particular.

Ao investirem nas teorias e práticas que fabricam o público, os agentes constituem a esfera cuja singularidade repousa em transformar a palavra em objetividade, na medida em que o enunciado arbitrário, falado em primeira pessoa do singular, transforma-se magicamente em palavra com força coletiva. Esse vocábulo servirá para fixar a solução, mas também para bloquear novos sentidos do universal ("não atende ao interesse coletivo", "é desvantajoso ao erário", entre outros).

Uma teoria das capacidades estatais tem que interagir com o Estado como fenômeno relacionado à representação sobre a ideia do que vem a ser esta coisa a que chamamos de público. A história do Estado, de certo modo, é a história de nosso pensamento sobre o Estado, no sentido de que a legitimidade das práticas e discursos sobre o público radica na crença de que atendem ao interesse coletivo. Aí reside o lastro pelo qual cada sociedade delega ao poder público um conjunto de obrigações e possibilidades, em termos de práticas autorizadas por representações do interesse universal.

A ideia de Estado como razão imparcial é apenas a teoria oficial sobre o oficial. O próprio Weber, lembrado como autor da tese da burocracia como tecnicamente superior a outras formas organizacionais, assinalou os limites da administração burocrática (Weber, 1982). O sociólogo alemão afirma que quando as massas postulam a justiça substantiva, seu ethos entra em choque com o formalismo e a "objetividade" fria das regras burocráticas, devendo rejeitá-las. No entanto, o ponto central é apreender o poder de cada agente estabelecer o que é essa justiça substantiva, de modo que se atribui pesos distintos à palavra, a depender de quem a enuncia, com a finalidade de reconstituir a lógica do oficial ao recusar aquilo que se nomeia como "razão de Estado".

Os conteúdos específicos que, mediante à luta social, preenchem o signo vazio do interesse público, articulando representações e instrumentos, têm caráter arbitrário. $\mathrm{O}$ que pode ser ilustrado pelo debate atual no Brasil em torno do abuso de autoridade dos agentes públicos. Qual o limite, por exemplo, para um agente público obter provas em um processo penal? Diante da representação do Brasil como país moralmente inferior (Souza, 2015), até a prova ilícita, uma vez obtida de boa-fé, nos termos de alguns agentes 
oficiais $^{11}$, e, no limite, a tortura, constituiriam instrumentos aceitáveis, depreendendo-se a boa-fé, na medida em que tais agentes sejam reconhecidos como moralizadores da nação.

O ponto é quem e como se define a boa-fé, reiterando-se que os instrumentos estatais são socialmente válidos apenas se articulados a uma representação sobre o interesse coletivo. Não há exemplo mais claro de que as práticas estatais e o discurso sobre o que constitui o público formam duas séries cujos termos estão em estreita relação. As capacidades estatais dependem de quem está apto a associá-las.

\section{Referências}

AGUILAR VILLANUEVA, Luis Felipe. Introducción. In: MAJONE, Giandomenico. Evidencia, argumentación y persusasión en la formualción de políticas. México: Fondo de Cultura Económica, 2005.

BAUMGARTNER, Frank; JONES, Bryan; MORTENSEN, Peter. Punctuated-equilibrium theory: explaining stability and change in public policymaking. In: SABATIER, Paul; WEIBLE, Cristopher. (Eds). Theories of the policy process. Boulder, Estados Unidos: Westview Press, 2014.

BERMAN, Paul. The study of macro and micro implementation of social policy. Santa Monica:The Rand Paper Series, 1978.

BOURDIEU, Pierre. A delegação e o fetichismo político. In: . Coisas ditas. São Paulo: Brasiliense, 1990. O Poder simbólico. Rio de Janeiro: Bertrand Brasil, 2006.

Sobre o Estado. São Paulo: Companhia das Letras, 2014.

BRESSER-PEREIRA, Luiz Carlos. Reflexões sobre a reforma gerencial brasileira de 1995. Revista do Serviço Público, n. 4, p. 5-29, 1999.

Editora, 2009.

Construindo o estado republicano no Brasil - democracia e reforma da gestão pública. Rio de Janeiro: FGV

CAMPOS, Gastão Wagner de Sousa; PEREIRA JÚNIOR, Nilton. A atenção primária e o Programa Mais Médicos do Sistema Único de Saúde: conquistas e limites. Ciência e saúde coletiva, v. 21, n. 9, p. 2.655-2.663, 2016.

CAPELLA, Ana Cláudia Niedhardt. Análise das políticas públicas: das técnicas às ideias. Ideias, v. 6, n. 2, p. 13-34, 2015.

CINGOLANI, Luciana. The State of State Capacity: a review of concepts, evidence and measures. UNUMERIT Working Paper Series, Maastricht University, 2013-053, p.1-52. Disponível em: < http://digitalarchive. maastrichtuniversity.nl/fedora/get/guid:25cb727f-2280-41f0-a1da-ecf3ac48230f/ASSET1>. Acesso em: 31 out. 2017.

CLINE, Kurt. Defining the implementation problem: organizational management versus cooperation. Journal of Public Administration Research and Theory, v. 10, n. 3, p. 551-571, 2000.

DELEUZE, Gilles. Lógica do sentido. São Paulo: Perspectiva, 2015.

DUR KHEIM, Emile. The elementary forms of the religious life. New York: The Free Press, 1965.

ELIAS, Norbert. O processo civilizador. v 2. Rio de Janeiro: Jorge Zahar Editor, 1993.

EVANS, Peter. The capability enhancing developmental state: concepts and national trajectories. Center for Studies on Inequality and Development, Texto para discussão, n. 63, 2011. Disponível em: $<$ http://www.proac.uff.br/cede/ sites/default/files/TD63.pdf>. Acesso em: 20 dez. 2016.

FOUCAULT, Michel. A arqueologia do saber. Rio de Janeiro: Forense Universitária, 2016.

11 BRASIL. Ministério Público Federal (MPF). 10 Medidas contra a corrupção. s. d. Disponível em: < http://www.dezmedidas.mpf.mp.br/>. Acesso em: 10 jan. 2017. 
FRASER, Nancy. Recognition without ethics? Theory, Culture \& Society, v. 18, n. 2-3, p. 21-42, 2001.

GOFFMAN, Erving. Ritual de interação - ensaios sobre o comportamento face a face. Petrópolis: Editora Vozes, 2011.

GUSFIELD, Joseph. Moral passage: the symbolic process in public designations of deviance. Social problems, n. 15, p. $175-188,1967$. Press, 1984.

The culture of public problems: drinking-driving and the symbolic order. Chicago: The University of Chicago

HAAJER, Maarten; LAWS, David. Ordering through discourse. In: MORAN, Michael et al. (Ed.). The Oxford handbook of public policy. Oxford: Oxford University Press, 2006.

HAAS, Peter. Introduction: epistemic communities and international policy coordination. International organization, v. 46, n. 1, p. $1-35,1992$.

HABERMAS, Jürgen. Três modelos normativos de democracia. Lua Nova, n. 36, p. 39-53, 1995.

LASSWELL, Harold.The Policy Orientation. In: LERNER, Daniel; LASSWELL, Harold (Ed.). The Policy Sciences: recent developments in scope andmethod. Stanford: Stanford University Press, 1951.

A Pre-view of policy sciences. New York: American Elsevier, 1971.

LINDBLOM, Charles. The science of "mudling through". Public Administration Review, v. 19, n. 2, p. 79-88, 1959.

LOUREIRO, Maria Rita et al. Democracia, arenas decisórias e políticas públicas: o programa Minha Casa Minha Vida. In: PIRES, Roberto Rocha Coelho; GOMIDE, Alexandre de Ávila. Capacidades estatais e democracia: arranjos institucionais de políticas públicas. Brasília: Instituto de Pesquisa Econômica Aplicada, 2014.

MAJONE, Giandomenico. Evidencia, argumentación y persuasión en la formulación de políticas.México: Fondo de Cultura Económica, 2005.

WILDAVSKY, Aaron. Implementation as Evolution. In: PRESSMAN, Jeffrey; WILDAVSKY, Aaron (Ed.).Implementation. Berkeley: University of California, 1984.

MATLAND, Richard. Synthesizing the implementation literature: the ambiguity-conflict model of policy implementation. Journal of Public Administration Research and Theory, v. 2, n. 5, p. 145-174, 1995.

MAZMANIAN, Daniel; SABATIER, Paul. La implementación de la política pública: un marco de análisis. In: AGUILAR VILLANUEVA, Luis Felipe (Org.). La implementación de las politicas. México: Miguel Angel Porrua, 1993.

MOSCOVICI, Serge. Representações sociais. Petrópolis: Editora Vozes, 2003.

PIRES, Roberto Rocha Coelho; GOMIDE, Alexandre de Ávila. Governança e capacidades estatais. Revista de Sociologia e Política, v. 24, n. 58, p. 121-143, 2016.

PÜLZL, Helga; TREIB, Oliver. Implementing public policy. In: FISCHER, Frank; MILLER, Gerald; SIDNEY, Mara (Ed.). Handbook of public policy analysis: theory, politics and methods. New York: CRC Press, 2007.

SKOCPOL, Theda. Bringing the state back in: strategies of analysis in current research. In: EVANS, Peter; RUESCHEMEYER, Dietrich; SKOCPOL, Theda (Ed.). Bringing the state back in. Cambridge: Cambridge University Press, 1985.

SOUZA, Jessé. A tolice da inteligência brasileira: ou como o país se deixa manipular pela elite. São Paulo: Leya, 2015. WEBER, Max. Ensaios de sociologia. Rio de Janeiro: LCT, 1982.

WEIBLE, Cristopher; SABATIER, Paul. A guide to the advocacy coalition framework. In: FISCHER, Frank. MILLER, Gerald; SIDNEY, Mara (Ed.). Handbook of public policy analysis: theory, politics and methods. New York: CRC Press, 2007.

ZITTOUN, Philippe. Hacia un enfoque pragmático de la acción pública. Revista Latinoamericana de Políticas y Acción Pública, v. 3, n. 2, p. 9-32, 2016.

The political process of policymaking: a pragmatic approach to public policy. Houndmills, Londres: Palgrave Macmillan, 2014. 


\title{
Public policies and language: the role of official definitions for building state capacities
}

\begin{abstract}
The purpose of this article, whose nature is theoretical and methodological, is to demonstrate the state capacities approach should apprehend the bureaucratic field as a symbolic dimension too. We consider the state actions, according to Pierre Bourdieu, construct principles of vision and division universally recognized, producing concrete effects on social reality. We intend to show that state agents concentrate symbolic power by which they create a language of public order and produce universal propositions that define, in interaction with other agents, a space of possible for public policies, whose instruments only exist if based on recognized definitions of public interest. The article concludes that state capacities depends on the distribution of power among agents for creating official legitimate definitions, articulating series of social representations and instruments of action socially authorized.
\end{abstract}

Keywords: state capacities, symbolic power, Pierre Bourdieu, social representations, public policies.

\section{Políticas públicas y lenguaje: el papel de las definiciones oficiales para la construcción de las capacidades estatales}

\section{Resumen}

El objetivo de este trabajo, de naturaleza teórica y metodológica, es demostrar que el enfoque de las disposiciones estatales debe captar el campo burocrático también en su dimensión simbólica. Por eso se considera que los actos de Estado, conforme a la teoría de Pierre Bourdieu, construyen principios de visión y división reconocidos universalmente, produciendo efectos sobre la realidad social. Se demostrará que los agentes estatales concentran poder simbólico por el que elaboran el lenguaje del orden público y se producen proposiciones universales que definen, en interacción con otros agentes, un espacio de posibilidades para las políticas públicas, con instrumentos que sólo existen basados en un conjunto de definiciones reconocidas por el interés común. Se concluye que las disposiciones estatales dependen de la distribución del poder entre los agentes para crear definiciones legítimas, mediante la articulación deseries de representaciones sociales y de instrumentos de acción socialmente autorizados como prácticas públicas.

Palabras clave: capacidades estatales, poder simbólico, Pierre Bourdieu, representaciones sociales, políticas públicas. 
